\title{
The identification method of blade material parameters and dynamic response analysis of impact
}

\author{
Xu Yu, Cheng Ming, Liu Jing-Yuan, Cheng Li \\ College of Aeronautical Engineering, Air Force Engineering University, CHINA \\ e-mail: xu_yuu@foxmail.com, cheng_ming@tom.com,firdsh@sina.com,cheng_qiaochu@foxmail.com
}

\section{SUMMARY}

Caused by the foreign object damage (FOD), failure usually occurs within a very short time so there are many uncertainties about it and it is difficult for experimental instruments to monitor their dynamic response. Therefore, the dynamic response of the impact must be analysed by means of numerical simulation. But, there is a severe lack of the dynamic mechanical performance parameters of the structural materials involved. In this research, the first-class fan titanium alloy blade of a turbofan engine was used as a specimen to carry out the FOD test. The test results show that the crack damage has obvious morphological characteristics and narrow parameter range. Based on the results of the FOD test, the reverse identification of Johnson-Cook model parameters is used and the finite element model of the foreign object impacting blade is constructed. Finally, the dynamic response of the impact is analysed from the perspective of different strengths applied and contact forces, which further proves the scientific and engineering value of the model.

KEY WORDS: $\quad$ blade; foreign object damage (FOD); numerical analysis; hard foreign object; damage morphology.

\section{INTRODUCTION}

Foreign object damage (FOD) [1] of a blade caused by a hard foreign object is a common aeroengine failure and occurs suddenly on the blade with complex surface structure, so it is difficult for the detection equipment to capture the change of physical quantity during the impact process. In order to obtain quantitative analysis of the macro and micro structure of the damage, we suggest the use of a finite element model that involves dynamic response on the blade impacted by the foreign object. Due to the many uncertain factors of the impact event, the dynamic mechanical parameters of the structural materials lack seriously so the construction of the finite element model is very difficult. Therefore, the determination of the blade material model parameters is the key issue when analysing the dynamic response.

As early as in the 1980s, Nicholas [2] studied the damage of titanium alloy flat sample caused by small hard object, and put forward the concept of quantitative description of the FOD; and 
in 2001, Ruschau et al. [3, 4] simulated the FOD damage to the compressor blade in condition of hard object impact test, and studied the effect of the FOD on fatigue strength. Since 2006, scholars all over the world have done more in-depth studies on the FOD and its dynamic response model. For example, Yin and Qian [5] studied the load model of blade impacted with soft and hard foreign objects; Spanrad and Tong [6] observed the damage characteristics of simulated blade, including notch indentation, material loss, material piling, shear band and micro-crack; Hu Xuteng et al. [7] studied the role of state equation in the FOD numerical simulation of engine blade, and showed that the selection of material constitutive model was very important for the FOD numerical simulation; Li Junsheng et al. [8] conducted numerical simulation of the damage process of a blade caused by steel ball, and proposed the concepts of relative energy and critical damage energy; Bao et al. [9] conducted the FOD simulation test at different impact angles and studied the relationship between the impact angle/impact damage size and the HCF strength; Zhao Zhen-Hua et al.[10] did the FOD simulation test for stainless steel plate sample and studied the relationship between the damage characteristics and the fatigue strength; Yang et al. [11] used the momentum theorem to derive the velocity equation of the foreign object moving in the airway, and took a blade as the reference system to establish the equation of the impact speed and impact angle of foreign object.

The research is first carried on the primary titanium alloy fan blade of a certain engine type and adopts the research approaches from both general and specific aspects to study the forming mechanism of the FOD damage on a blade and the parameter identification of dynamic response model. From the general aspect approach, in this research the FOD simulation test was carried out to study the damage regularity under different conditions and the finite element model of a blade was created to study the changes of energy and contact force in the impact process.

\section{THE FOD SIMULATION TEST AND TYPICAL DAMAGE MORPHOLOGY}

\subsection{THE FOD TEST DEVICE}

The FOD simulation test was carried out based on air cannon test system (Figure 1). The sample was clamped on the fixture, and the valve was opened to rush out the foreign object through the expansion of the high-pressure gas. Then the foreign object accelerated in the gun tube with its incidence rate measured through fibre velocimeter, and the impact speed could be regulated by adjusting the pressure value. The fixture of the sample was adjusted to simulate the damages caused by the foreign objects approaching from different angles.

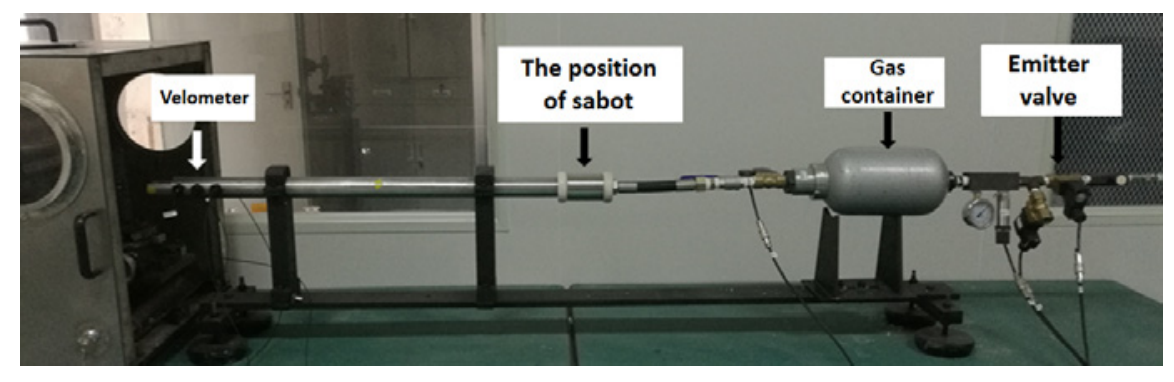

Fig. 1 Air cannon test system 
When large force is applied, steel ball usually is slightly deformed in the impact event. Therefore, during the testing the steel ball with a diameter of $3 \mathrm{~mm}$ was used to simulate a foreign object to focus on the deformation and damage of the blade during the test.

\subsection{TEST SUBJECT}

The primary titanium alloy fan blade of certain engine type was used as the test subject. This engine is a fan engine with high thrust and small bypass ratio and is widely used in the power unit of third generation warcraft. Figure 2 shows the geometry of the blade. It is made of BT3-1 titanium alloy and has the microstructure of the same structure. It is composed of primary $\alpha+\beta$ phases.

The blade has the fan rotor with the maximum speed of 10,098 rpm and can work within the hub-line and tip-line speed ranges of $57.90 \mathrm{~m} / \mathrm{s} \sim 192.99 \mathrm{~m} / \mathrm{s}$ and $141.69 \mathrm{~m} / \mathrm{s} \sim 472.31 \mathrm{~m} / \mathrm{s}$, respectively. Therefore, different speeds within the range of $80 \mathrm{~m} / \mathrm{s} \sim 350 \mathrm{~m} / \mathrm{s}$ were selected to impact the inlet edge of the primary blade.

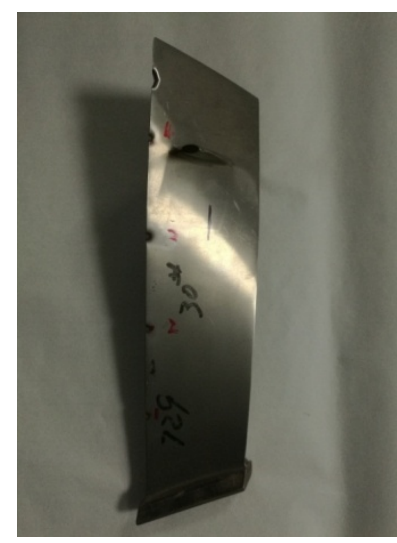

(a)
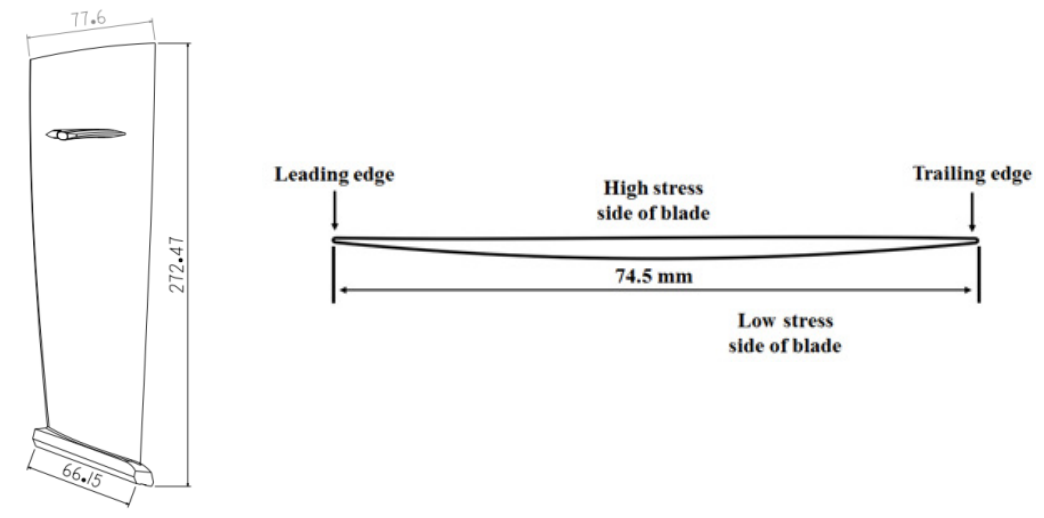

Fig. 2 (a) Primary fan blade of certain fan type engine (b) Cross section of blade

The blade's inlet edge was measured to the thickness of $0.5 \pm 0.03 \mathrm{~mm}$ at $20 \%$ blade height, and the test was carried out at the different positions selected between $20 \%$ and $100 \%$ blade height.

This research showed that: foreign objects impact the blades at the angle of incidence from $30^{\circ}-60^{\circ}$ in relation to the blade's centre line (Figure 3), [12]. To simulate the actual impact damage process caused by a foreign object, two incidence angles one of $30^{\circ}$ and the other of $60^{\circ}$ were selected to carry out the tests, respectively. 


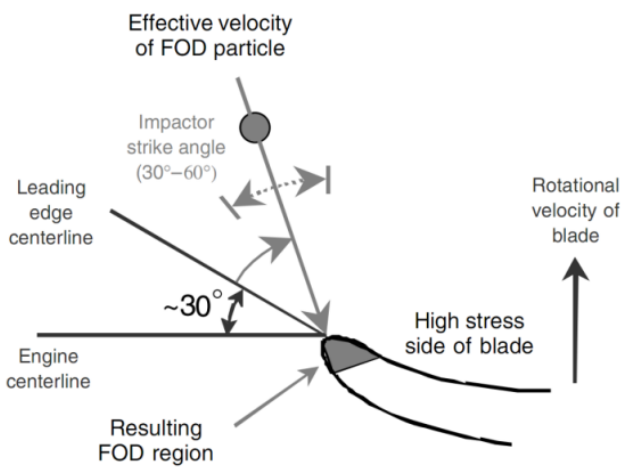

Fig. 3 Schematic diagram of a foreign object impacting the blade from different angles

\subsection{TEST RESULTS AND DAMAGE MORPHOLOGY ANALYSIS}

With 3D video microscope, the macroscopic damage morphology of simulated FOD was observed and it was found that three types of blade damage morphologies occurred during the test process: the indentation damage morphology, the crack damage morphology and the notch damage morphology (Figure 4). These three damage morphologies were distinguished from each other according to the damage degree of the blade on impact: the indentation damage morphology refers to the phenomenon that the blade is extruded and deformed at the impact point but none of the parts tear off; the crack damage morphology refers to the phenomenon that the blade is cracked at the impact point but does not tear off completely; and the notch damage morphology refers to the phenomenon that the blade has obvious shear damage or tears off. This test proved that the occurrence frequency of the notch damage morphology was proportional to the impact speed while the occurrence frequency of the indentation damage morphology was inversely proportional to the impact speed, so the crack damage morphology was regarded as the transitional one from the indentation damage morphology to the notch damage morphology.

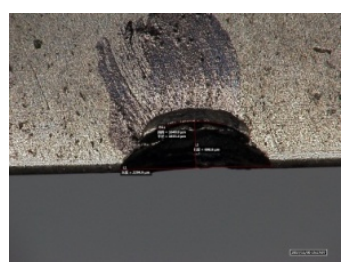

a) Dent

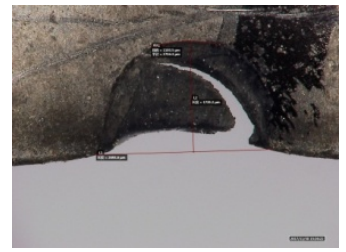

b) Tear

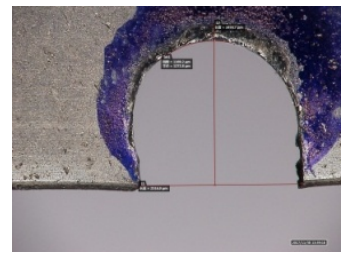

c) Notch

Fig. 4 Typical damage morphologies

Figure 5 shows the damage morphologies of the inlet edge of the blade impacted with a foreign object at the speed of $350 \mathrm{~m} / \mathrm{s}-100 \mathrm{~m} / \mathrm{s}$ and an impact angle of $60^{\circ}$. It can be concluded that the speed of about $170 \mathrm{~m} / \mathrm{s}$ was the critical value: the crack damage morphology occurred when a foreign object approached at the speed of about $170 \mathrm{~m} / \mathrm{s}$; the notch damage morphology occurred more frequently when a foreign object approached at a speed of more than $170 \mathrm{~m} / \mathrm{s}$; and the indentation damage morphology occurred more frequently when a foreign object approached at the speed of less than $170 \mathrm{~m} / \mathrm{s}$. Therefore, the speed of $170 \mathrm{~m} / \mathrm{s}$ was regarded as the damage critical speed at the impact angle of $60^{\circ}$. 


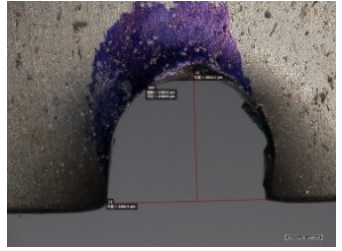

a) $350 \mathrm{~m} / \mathrm{s}$

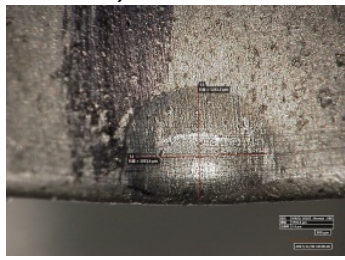

d) $160 \mathrm{~m} / \mathrm{s}$

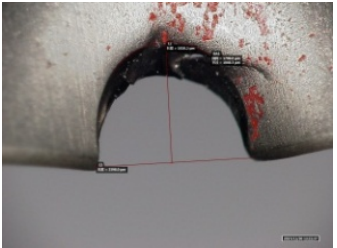

b) $280 \mathrm{~m} / \mathrm{s}$

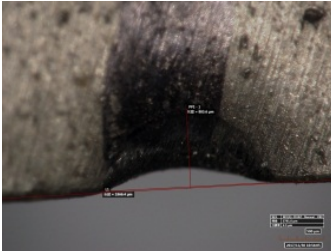

e) $120 \mathrm{~m} / \mathrm{s}$

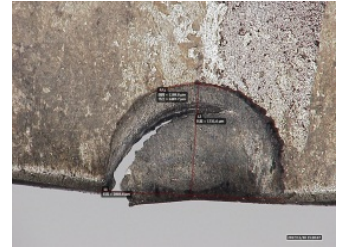

c) $170 \mathrm{~m} / \mathrm{s}$

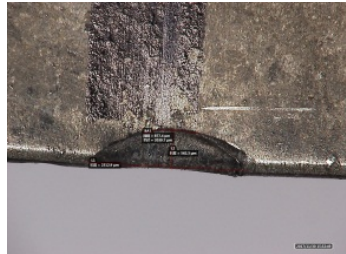

f) $100 \mathrm{~m} / \mathrm{s}$

Fig. 5 Damage morphologies at an impact angle of $60^{\circ}$

Figure 6 shows that the damage morphologies at the impact angle of $30^{\circ}$ did not have clear damage critical speeds in comparison with the damage morphologies at the impact angle of $60^{\circ}$, and the crack damage morphologies occurred when the foreign object approached at the speeds of $200 \mathrm{~m} / \mathrm{s}$ and $160 \mathrm{~m} / \mathrm{s}$. Therefore, the damage critical speed the impact angle of $30^{\circ}$ was speculated to be in the range of $140 \mathrm{~m} / \mathrm{s}-200 \mathrm{~m} / \mathrm{s}$.

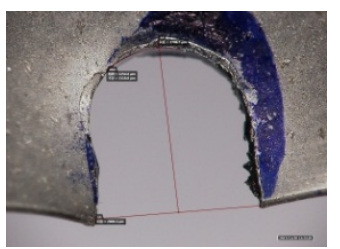

a) $350 \mathrm{~m} / \mathrm{s}$

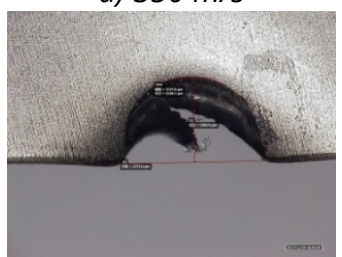

d) $160 \mathrm{~m} / \mathrm{s}$

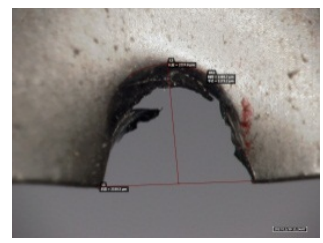

b) $280 \mathrm{~m} / \mathrm{s}$

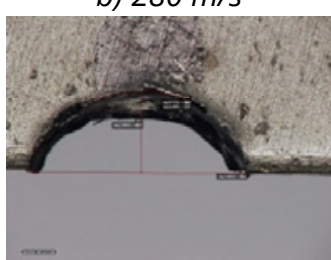

e) $140 \mathrm{~m} / \mathrm{s}$

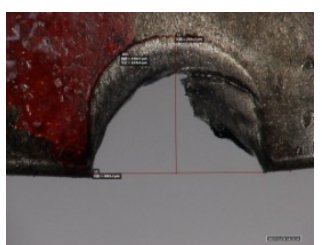

c) $200 \mathrm{~m} / \mathrm{s}$

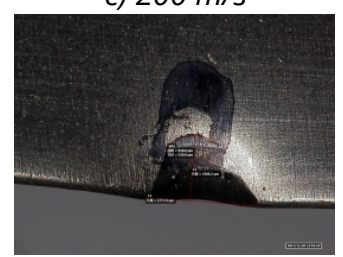

f) $120 \mathrm{~m} / \mathrm{s}$

Fig. 6 Damage morphologies at an impact angle of $30^{\circ}$

\section{FINITE ELEMENT MODELLING AND MODEL PARAMETER IDENTIFICATION}

\subsection{MATERIAL MODEL}

The event of the foreign object impacting the blade refers to plastic failure and collision damage of high-strain material. In order to describe the dynamic deformation behaviour of metal material, scholars have successively proposed several models including the JohnsonCook material model, the Zerilli-Armstrong model and the Bammann model. Among them, the Johnson-Cook material model is widely used because it has simple form and few parameters that can be obtained easily by fitting. For example, Ji Yuhui [13], Pan Hui [14] and Lin et al. [15] all adopted the Johnson-Cook material model and acquired better simulation of the FOD 
process. In our research we also adopted the Johnson-Cook material model and expressed its constitutive model as follows:

$$
\sigma_{y}=\left(A+B \varepsilon_{p}^{n}\right)\left(1+C \ln \dot{\varepsilon}^{*}\right)\left(1-T^{* m}\right)
$$

where $\sigma_{y}$ is the yield stress; $A, B, n, C$ and $m$ are the material parameters; $\varepsilon_{p}$ is the equivalent plastic strain; $\dot{\varepsilon}^{*}=\dot{\varepsilon}_{p} / \dot{\varepsilon}_{0}$ is the non-dimensional equivalent plastic strain rate; $\dot{\varepsilon}_{0}$ is the reference strain rate; $T^{*}=\left(T-T_{r}\right) /\left(T_{m}-T_{r}\right)$ is the non-dimensional temperature; $T_{r}$ is the reference temperature, usually referring to the room temperature; and $T_{m}$ is the material melting temperature, and $T$ is the current temperature.

The Johnson-Cook failure model is expressed as follows:

$$
\varepsilon_{f}=\left(D_{1}+D_{2} \exp \left(D_{3} \sigma^{*}\right)\right)\left(1+D_{4} \ln \dot{\varepsilon}^{*}\right)\left(1-D_{5} T^{*}\right)
$$

where $\varepsilon_{f}$ is the failure (plastic) strain; $D_{1}-D_{5}$ are the failure parameters; $\sigma^{*}$ is the ratio of hydrostatic pressure to equivalent stress.

Material parameters and failure parameters of the model are required when Eqs. (1) and (2) are used in numerical simulation, and the material model parameters of the primary titanium alloy fan blade of the engine are needed to screen and identify because the blade was made with the die forging process since its dynamic mechanical properties cannot be obtained in a straightforward manner.

According to the FOD simulation test results, different damage morphologies were formed when the foreign object impacted the blade under certain conditions. Among them, the crack damage morphology, as the transitional morphology of the typical damage morphology, had relatively small range of impact speed and can be taken as the standard for model parameter identification.

\subsection{REVERSE IDENTIFICATION OF MATERIAL PARAMETERS}

In this research, Abaqus was used to build a numerical analysis model for the FOD impact on a blade. Since foreign object impact on the blade only caused local damage, in order to improve the calculation efficiency, the damaged part of the blade was excluded when building a simulation model. The blade and steel ball were modelled using the C3D8R element (8-node linear brick, reduced integration with hourglass control), Figure 7. To be precise, the unit numbers of the blades and steel balls were 47232 and 1187, respectively.

Due to the lack of dynamic mechanical properties data of BT3-1 titanium alloy, the JohnsonCook (JC) material parameters for Ti-6Al-4V alloy taken from the literature [14] were applied. However, it is obvious that the FOD test results of BT3-1 titanium alloy cannot be accurately predicted using these parameters, so, we had to correct these parameters. In order to perform it, we adopted trial-and-error to correct these parameters. We constantly compared the experimental results with the numerical simulation results through iterative FE analyses and calibrated constantly the parameters according to the results of the comparison. The modified Johnson-Cook parameters which we eventually applied are shown in Tables 1 and 2. 


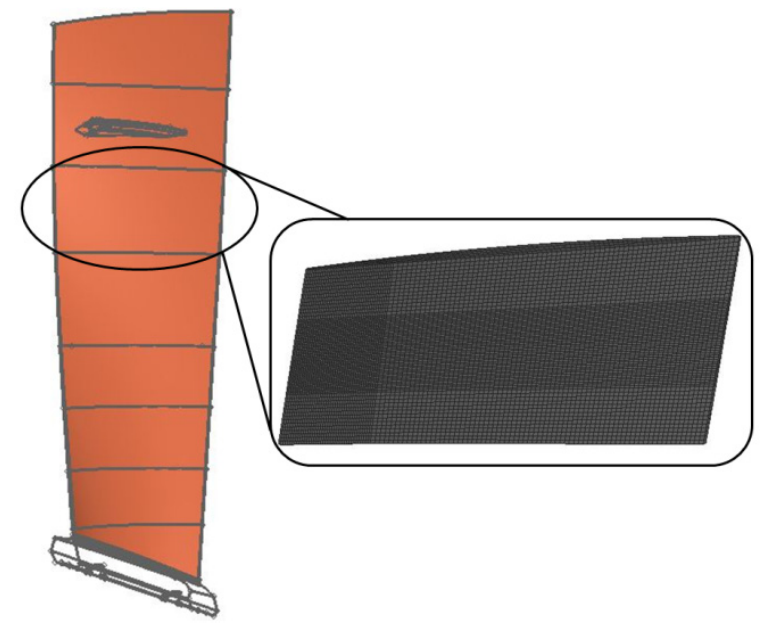

Fig. 7 Grid model of a blade

Table 1 Constitutive model parameters

\begin{tabular}{ccccc}
\hline$A / M P a$ & $B / M P a$ & $n$ & $C$ & $m$ \\
150 & 250 & 0.3410 & 0.0182 & 0.7672 \\
\hline
\end{tabular}

Table 2 Failure model parameters

\begin{tabular}{ccccc}
\hline$D_{1}$ & $D_{2}$ & $D_{3}$ & $D_{4}$ & $D_{5}$ \\
-0.09 & 0.27 & 0.48 & 0.014 & 3.87 \\
\hline
\end{tabular}

On the basis of these material parameters, the finite element model of the damage to the blade caused by a hard foreign object was successfully built. The comparison of simulation and test results at the impact angle of $60^{\circ}$ is shown in Figure 8. We conclude that the simulated damage morphologies were consistent with the damage morphologies in the test at different impact speeds and impact angles.

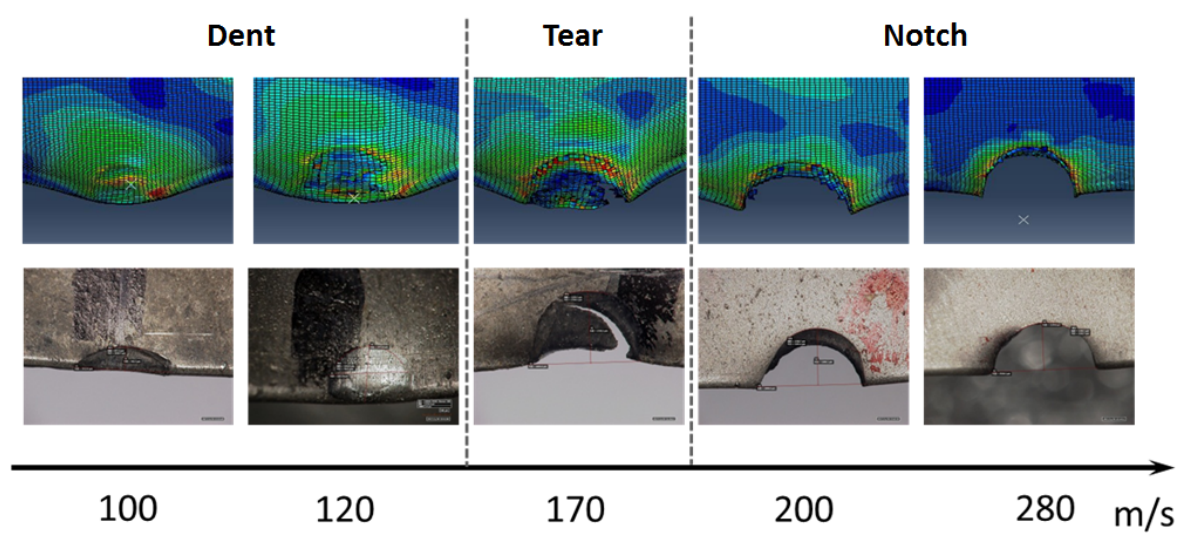

Fig. 8 Comparison of simulation and test results at the impact angle of $60^{\circ}$ 
The dynamic finite element model was used to do the numerical simulation of the test at the impact angle of $30^{\circ}$, and the results showed that the simulation results were consistent with the test results (Figure 9), which further showed that the model could effectively simulate the test process impacted by a foreign object. Moreover, the simulation results in Figure 9 indicated that the crack damage morphology occurred at the impact speed of $160 \mathrm{~m} / \mathrm{s}$, and the FOD test results confirmed that the damage critical speed was $160 \mathrm{~m} / \mathrm{s}$ at the impact angle of $30^{\circ}$.

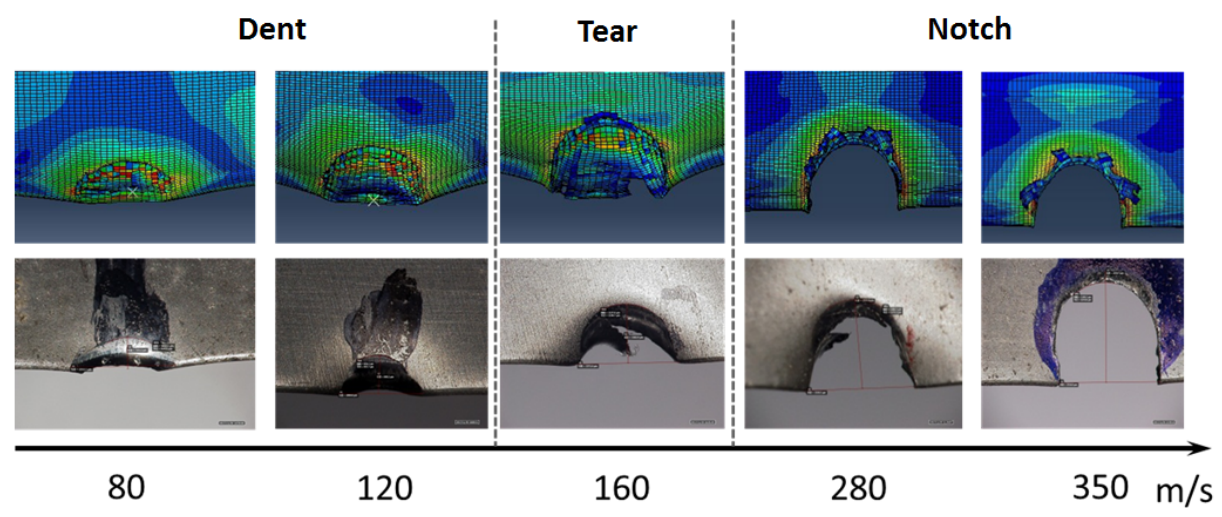

Fig. 9 Comparison of simulation and test results at the impact angle of $30^{\circ}$

\section{SIMULATION ANALYSIS OF IMPACT ENERGY AND CONTACT FORCE}

It is difficult for the detection equipment to accurately capture the changes of physical quantities such as kinetic energy, contact force and strain energy during the impact event due to the facts that the FOD usually occurs within a very short time and the primary fan blade of the engine has a complex structure. Considering these difficulties, the FOD dynamic response model was used to analyse the energy and contact force in the impact event to explore the forming mechanism for quantitatively studying the FOD damage.

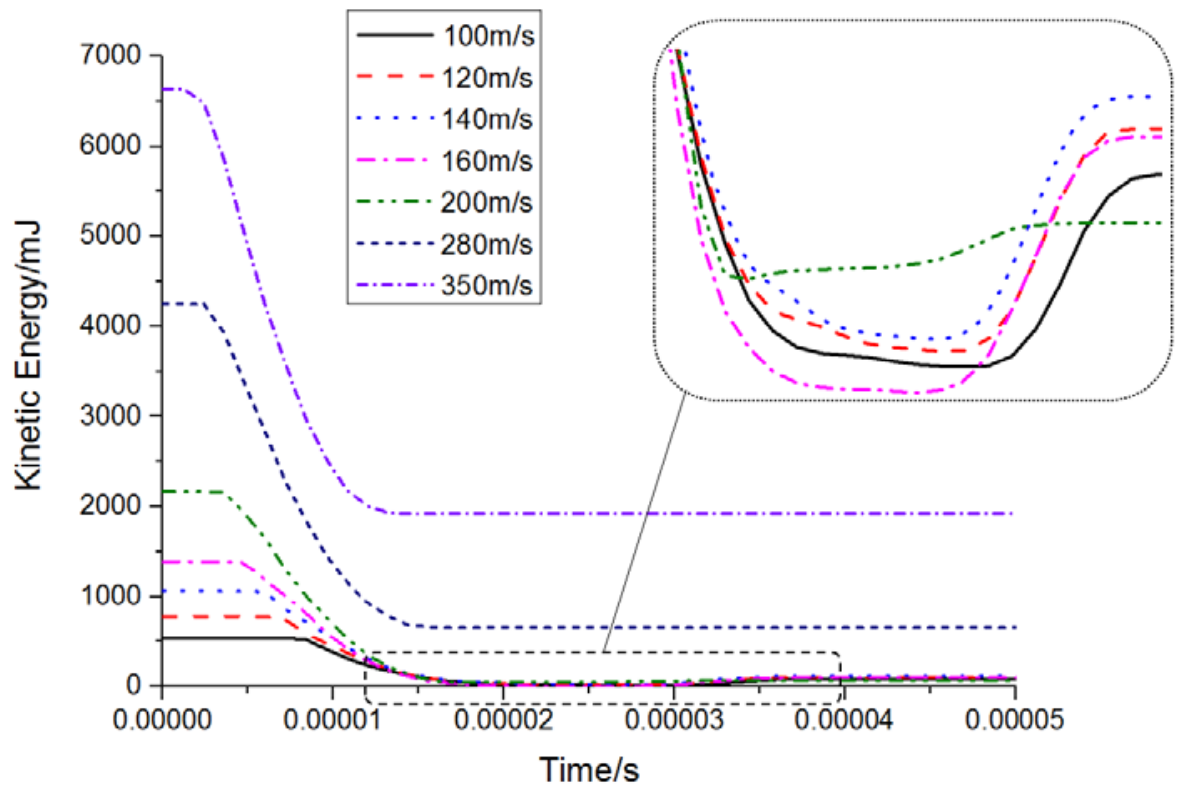

Fig. 10 Kinetic energy change of a steel ball impacted by a foreign object 
Figure 10 shows the changes of the kinetic energies of the $3 \mathrm{~mm}$ steel ball when it impacts the blade at different speeds and different angles. Since the initial kinetic energy of the steel ball represents the total energy of the whole model, the change of kinetic energy of steel ball indirectly reflects the change of energy absorbed by the blade. Figure 10 shows that, regardless of the impact speed, the kinetic energy loss of the steel ball at the impact angle of $30^{\circ}$ was greater than that at the impact angle of $60^{\circ}$, further showing that the blade absorbed more energy at the impact angle of $30^{\circ}$.

Figure 11 shows the changes of kinetic energy losses along with speed at different impact angles.

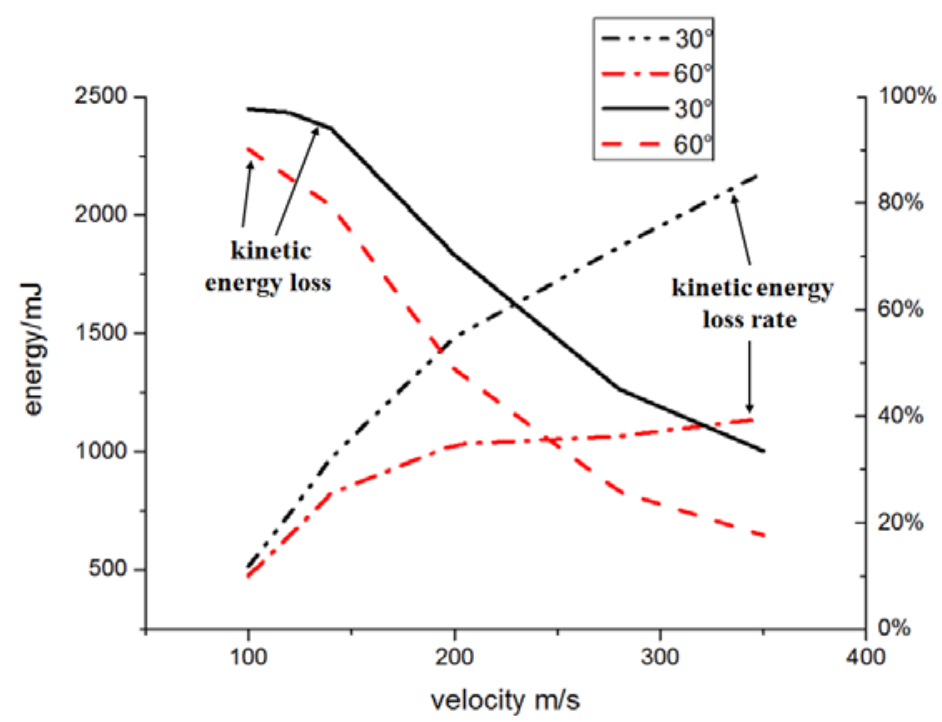

Fig. 11 Change of kinetic energy loss of steel ball

Figure 12 shows the time curve of the impact contact force of the steel ball impacting the blade at different angles and speeds.

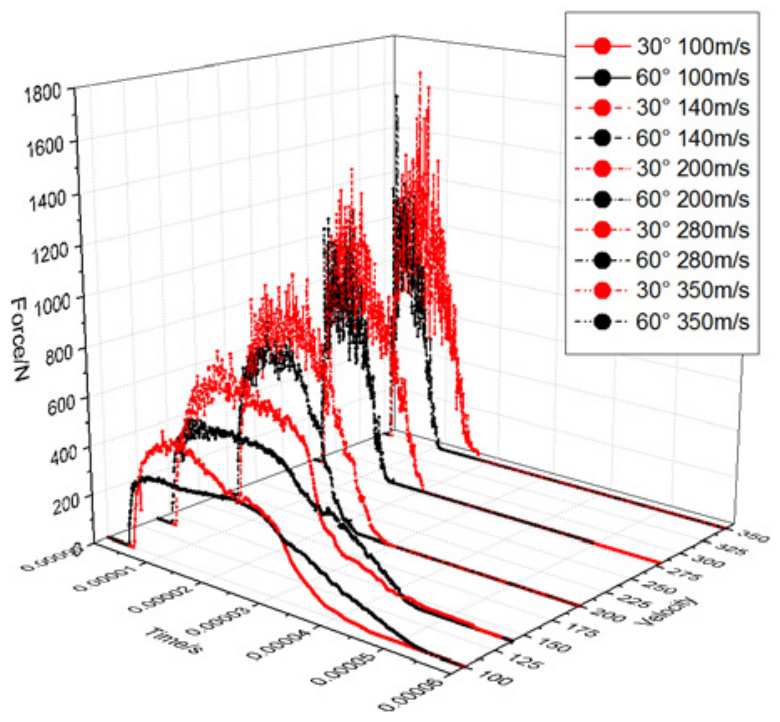

Fig. 12 Contact force of a steel ball impacting a blade 
The impact force at impact angle of $30^{\circ}$ is obviously higher than that at impact angle of $60^{\circ}$. However, with the increase of velocity, the gap between them decreases, and the maximum contact force between them is basically the same when high-speed impact occurs. When the steel ball impacted the blade at an impact angle of $30^{\circ}$, its impact contact force lasted longer. Therefore, we concluded that the steel ball had stronger penetration of the blade when it impacted at an impact angle of $30^{\circ}$.

Figure 13 shows the change of the strain energy of the blade that reflects the residual stress field on the blade to some extent.

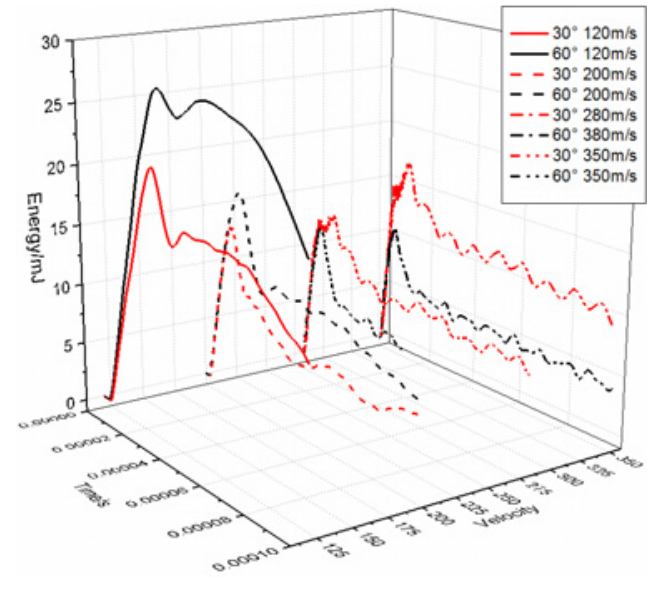

a)

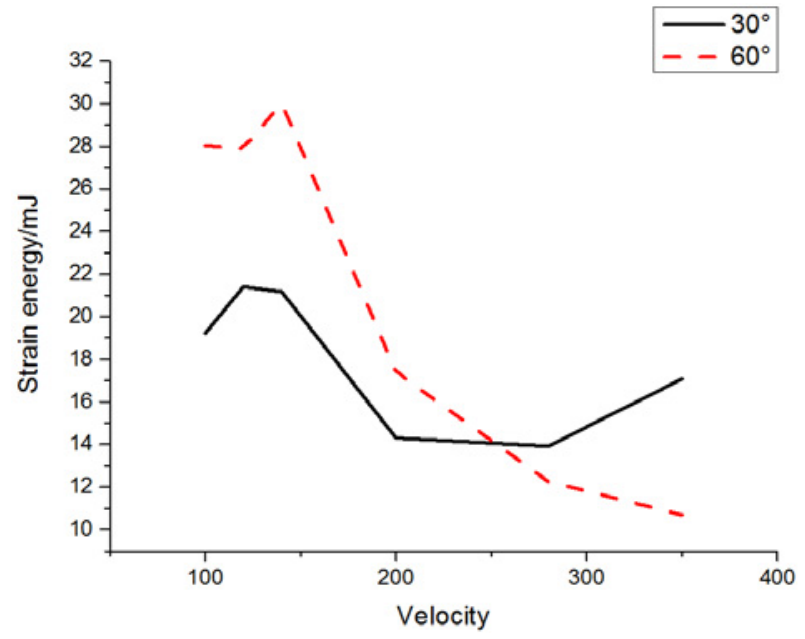

b)

Fig. 13 Strain energy change of the blade impacted by a steel ball: a) Change of strain energy of blade; b) Variation of maximum strain energy of blade

The strain energy was also considered since it can reveal the microstress characteristics of the FOD damage. When the steel ball hits the blade at low speed, the strain energy of the blade at an impact angle of $60^{\circ}$ is significantly higher than the strain energy at $30^{\circ}$. However, as the speed increases, the difference between the two decreases. When the impact velocity is higher than $250 \mathrm{~m} / \mathrm{s}$, the strain energy of the blade at an impact angle of $30^{\circ}$ is higher than at $60^{\circ}$. Therefore, the blade produced larger residual stress field when it was impacted by the steel ball at a low speed and at the impact angle of $60^{\circ}$, and the blade produced significantly larger residual stress field when it was impacted by the steel ball at a high speed and at the impact angle of $30^{\circ}$. Figure 13 (b) shows that the maximum strain energy of the blade increased slightly and then fell suddenly when the steel ball impacted the blade at a low speed regardless the impact angle either of $30^{\circ}$ or $60^{\circ}$. This change can be explained as follows: when the steel ball impacted the blade at the angles of $30^{\circ}$ and $60^{\circ}$, its damage critical speeds were $160 \mathrm{~m} / \mathrm{s}$ and $170 \mathrm{~m} / \mathrm{s}$, respectively; so before the steel ball reached the critical speed, the blade on impact had the indentation damage morphology and was deformed locally so that the strain energy was accumulated accordingly; and after the steel ball exceeded the critical speed, the blade, on impact, acquired the crack or notch damage morphology and was either cracked or thorn off so that the strain energy was released. 


\section{CONCLUSIONS}

This paper deals with the research based on the use of the primary titanium alloy fan blade of certain fan engine type to carry out the FOD simulation test. The parameter identification of the Johnson-Cook model was also used, a dynamic response model of the blade impacted by a hard foreign object was created, the energy and contact force produced during the impact event were analysed, which all led to the following conclusions:

(1) A real blade was used to carry out the FOD test research and the crack damage morphology was regarded as a transitional morphology: the primary fan blade of certain type of fan engine was subject to the FOD simulation test under certain conditions and formed three typical damage morphologies including the indentation damage morphology, the crack damage morphology and the notch damage morphology, among which the crack damage morphology was a transitional morphology.

(2) A parameter identification method of the FOD model of the blade with damage morphologies was proposed. Specifically, in this paper the crack damage morphology is taken as the basis for parameter identification, the parameters of the Johnson-Cook model were identified through numerical simulation and optimization, and the dynamic response model of the blade impacted by a hard foreign object was created so that the calculated results were consistent with the test results.

(3) In this paper, the macroscopic and microscopic stress characteristics of the FOD to blade were preliminarily revealed with the use of the finite element model in analyzing the energy change and contact force in the impact event: the blade absorbed more energy and had stronger penetration at the impact angle of $30^{\circ}$, and produced more residual stress field when it was subjected to a high-speed impact.

\section{REFERENCES}

[1] Y.P. Guan, C. Wei and D.P. Gao, Present status of investigation of foreign object damage to blade in aeroengine, Acta Aeronautica Et Astronautica Sinica, Vol. 28, No. 4, pp. 851-857, 2007. https://doi.org/10.3321/j.issn:1000-6893.2007.04.014

[2] T. Nicholas, Tensile testing of materials at high rates of strain, Experimental Mechanics, Vol. 21, No. 5, pp. 177-185, 1981. https://doi.org/10.1007/BF02326644

[3] J.J. Ruschau, T. Nicholas and S.R. Thompson, Influence of foreign object damage (FOD) on the fatigue life of simulated Ti-6Al-4 V airfoils, International Journal of Impact Engineering, Vol. 25, No. 3, pp. 233-250, 2001.

https://doi.org/10.1016/S0734-743X(00)00044-0

[4] J. Ruschau, S.R. Thompson and T. Nicholas, High cycle fatigue limit stresses for airfoils subjected to foreign object damage, International Journal of Fatigue, Vol. 25, No. 9-11, pp. 955-962, 2003. https://doi.org/10.1016/S0142-1123(03)00135-X

[5] D.M. Yin and L.F. Qian, Impact damage analysis of blades due to impacts from soft body and hard one, Journal of Vibration \& Shock, Vol. 28, No. 3, pp. 6-9,13, 2009.

https://doi.org/10.3969/j.issn.1000-3835.2009.03.002 
[6] S. Spanrad and J. Tong, Characterization of foreign object damage (FOD) and early fatigue crack growth in laser shock peened Ti-6Al-4 V aerofoil specimens, Materials Science \& Engineering A, Vol. 528, No. 4, pp. 2128-2136, 2011. https://doi.org/10.1016/j.msea.2010.11.045

[7] X.T. Hu, X.Q. Zhang and Y.D. Song, Effect of equation of state on numerical simulation results of outer object damage to aeroengine blades, Aeronautical Computing Technique, 2, 2013. https://doi.org/10.3969/j.issn.1671-654X.2013.01.006

[8] L.I. Jun-Sheng, Q. Chai, B.Y. Yang, G.B. Zhang, Z.P. Zhang and G.X. Cao, Impact damage on one kind of aero-engine compressor blade from steel sphere, Journal of Air Force Engineering University, 2013. https://doi.org/10.3969/j.issn.1009-3516.2013.06.002

[9] Z.Q. Bao, X.T. Hu, and Y.D. Song, Effect of foreign object damage at different impact angles on high cycle fatigue strength of TC4 titanium alloys, Journal of Aerospace Power, Vol. 30, No. 9, pp. 2226-2233, 2015. https://doi.org/10.13224/j.cnki.jasp.2015.09.023

[10] Z-H. Zhao, W. Chen and Y-P. Guan, Effect of foreign object damage on fatigue strength of stainless steel, Journal of Aerospace Power, Vol. 31, No. 7, pp. 1736-1743, 2016.

https://doi.org/10.13224/j.cnki.jasp.2016.07.024

[11] B. Yang, Q. Chai, C. Li, J. Li, X. Wu and Z. Zhu, Estimation of velocity for foreign object that impacting rotor blade of aero-engine, Hangkong Dongli Xuebao/Journal of Aerospace Power, Vol. 32, No. 12, pp. 2842-2847, 2017.

https://doi.org/10.13224/j.cnki.jasp.2017.12.004

[12] T. Nicholas, High Cycle Fatigue: A Mechanics Of Materials Perspective, Elsevier, 2006. https://doi.org/10.1016/b978-0-08-044691-2.x5000-0

[13] Ji Yu-Hui, Research on numerical modelling of FOD basing Johnson-Cook material model [D], Nanjing University of aeronautics and astronautics, 2009. (in Chinese)

https://doi.org/10.7666/d.d076403

[14] Pan Hui, Research on damage characteristics and simulation test of foreign object damage of blade [D], Nanjing University of aeronautics and astronautics, 2012. (in Chinese)

[15] B. Lin, S. Zabeen, J. Tong, M. Preuss and P.J. Withers, Residual stresses due to foreign object damage in laser-shock peened aerofoils: simulation and measurement, Mechanics of Materials, Vol. 82, pp. 78-90, 2015. https://doi.org/10.1016/j.mechmat.2014.12.001 